\title{
Effectiveness and safety of metallic stent for ileocecal obstructive colon cancer: a report of 4 cases
}

\section{(ㄷ)(1) $\odot$}

Authors

Tatsuya Ishii ${ }^{1}$, Kosuke Minaga ${ }^{2}$, Satoshi Ogawa ${ }^{3}$, Maiko Ikenouchi ${ }^{1}$, Tomoe Yoshikawa $^{1}$, Takuji Akamatsu $^{1}$, Takeshi Seta ${ }^{1}$, Shunji Urai ${ }^{1}$, Yoshito Uenoyama1, Yukitaka Yamashita ${ }^{1}$

Institutions

1 Department of Gastroenterology and Hepatology, Japanese Red Cross Society Wakayama Medical Center, Wakayama, Japan

2 Department of Gastroenterology and Hepatology, Kindai University Faculty of Medicine, Osaka, Japan

3 Department of Gastroenterology and Hepatology, Kyoto University Graduate School of Medicine, Kyoto, Japan

submitted 16.8.2016

accepted after revision 2.5.2017

Bibliography

DOI https://doi.org/10.1055/s-0043-113560 |

Endoscopy International Open 2017; 05: E834-E838

(c) Georg Thieme Verlag KG Stuttgart · New York

ISSN 2364-3722
Corresponding author

Tatsuya Ishii, Department of Gastroenterology and

Hepatology, Japanese Red Cross Society Wakayama Medical

Center, 4-20 Komatsubaradori, Wakayama, 640-8558,

Japan

Fax: +81-73-426-1168

ttyisi141@outlook.com

\section{ABSTRACT}

Background and study aims Self-expandable metallic stents (SEMS) have been widely used for left-sided colorectal obstruction. Few studies on SEMS placement for right-sided colonic obstructions have been reported because stenting in the right colon is technically difficult, particularly in the ileocecal region. We present 4 cases of successful bridge-to-surgery stenting for ileocecal cancer. Using an endoscopic retrograde cholangiopancreatography catheter with a movable tip and a decompression tube was effective for stenting. No adverse events occurred during or after SEMS placement in any of these cases. Short-term stenting for ileocecal cancer seems to be effective and safe.

\section{Introduction}

Self-expandable metallic stents (SEMS) have been widely used for left-sided colorectal obstruction. Few studies on SEMS placement for right-sided colonic obstructions have been reported because the management of right-sided colonic obstruction differs from that of left-sided colonic obstruction. Right-sided colonic obstructions, including ileocecal obstructions, are usually managed with surgical resection and primary anastomosis. Stenting in the right colon, particularly the ileocecal region, is technically difficult. However, recent reports have shown that emergency right colon resection can be associated with high morbidity and mortality rates. Therefore, elective surgery is desirable for right-sided colonic obstructions. Herein, we describe four cases of successful metallic stenting for obstructive ileocecal cancer.

\section{Case Reports}

Three men and 1woman (mean age, 71 years; range, 63-77 years) underwent successful SEMS placement for obstructive ileocecal cancer between September 2014 and December 2015 in our institution ( Table 1). Their symptoms were nausea, vomiting, abdominal pain, and abdominal distention. Contrast-enhanced computed tomography (CT) scan revealed thickened ileocecal stenosis with proximal dilation of the colon and distal small intestine ( $\mathbf{F i g . 1 a , ~} \triangleright$ Fig. 1b). Three patients had liver metastases. In the first case, we inserted the decompression tube primarily, and the patient underwent SEMS placement after two days. Emergency SEMS placement was attempted in the remaining 3 cases. All 4 patients underwent enema preparation before endoscopy. The endoscopic procedures were performed with administration of a small amount of intravenous midazolam. A colonoscope (CF-HQ290, PCF-Q260AI; Olympus Medical System, Tokyo, Japan) was inserted into the stenosis site while washing the intestinal tract with water 
- Tab. 1 Clinical characteristics and outcomes of patients who underwent metallic stenting for obstructive ileocecal cancer. OP, operation; CT, chemotherapy

\begin{tabular}{|c|c|c|c|c|c|c|c|c|c|}
\hline Case & $\begin{array}{l}\text { Age/ } \\
\text { sex }\end{array}$ & Histopathology & $\begin{array}{l}\text { Clinical } \\
\text { stage }\end{array}$ & Stent & $\begin{array}{l}\text { Adverse } \\
\text { events }\end{array}$ & $\begin{array}{l}\text { Diet } \\
\text { pre/post }\end{array}$ & $\begin{array}{l}\text { Treat- } \\
\text { ment }\end{array}$ & $\begin{array}{l}\text { Surgical wait- } \\
\text { ing period }\end{array}$ & $\begin{array}{l}\text { Out- } \\
\text { come }\end{array}$ \\
\hline 1 & $66 / M$ & $\begin{array}{l}\text { Adenocarcinoma, } \\
\text { tub2 }\end{array}$ & IV & $\begin{array}{l}\text { Niti-S } \\
18 \mathrm{~mm} \text {, } \\
6 \mathrm{~cm}\end{array}$ & None & $\begin{array}{l}\text { No oral intake/ } \\
\text { low residue }\end{array}$ & $\mathrm{OP}+\mathrm{CT}$ & 20 days & $\begin{array}{l}\text { Died } \\
\text { (1year) }\end{array}$ \\
\hline 2 & $77 / \mathrm{M}$ & $\begin{array}{l}\text { Adenocarcinoma, } \\
\text { tub1 }\end{array}$ & IIB & $\begin{array}{l}\text { Niti-S } \\
18 \mathrm{~mm} \text {, } \\
6 \mathrm{~cm}\end{array}$ & None & $\begin{array}{l}\text { No oral intake/ } \\
\text { low residue }\end{array}$ & $\mathrm{OP}$ & 21 days & Alive \\
\hline 3 & $63 / F$ & $\begin{array}{l}\text { Signet ring cell } \\
\text { carcinoma }\end{array}$ & IV & $\begin{array}{l}\text { Niti-S } \\
18 \mathrm{~mm}, \\
6 \mathrm{~cm}\end{array}$ & None & $\begin{array}{l}\text { liquid/ } \\
\text { low residue }\end{array}$ & $\mathrm{OP}+\mathrm{CT}$ & 21 days & Alive \\
\hline 4 & $76 / \mathrm{M}$ & $\begin{array}{l}\text { Adenocarcinoma, } \\
\text { tub2 }\end{array}$ & IV & $\begin{array}{l}\text { Niti-S } \\
18 \mathrm{~mm} \text {, } \\
8 \mathrm{~cm}\end{array}$ & None & $\begin{array}{l}\text { liquid/ } \\
\text { low residue }\end{array}$ & $\mathrm{OP}+\mathrm{CT}$ & 19 days & Alive \\
\hline
\end{tabular}

( $\vee$ Fig. 2 a). When the ileus tube was placed, the contrast medium was injected from the oral side, revealing the stenosis and terminal ileum clearly ( $\bullet$ Fig. 1 c).

Under endoscopic and fluoroscopic guidance, an endoscopic retrograde cholangiopancreatography (ERCP) catheter was passed over the 0.025 -inch guidewire (Visiglide, Olympus). Inserting the catheter into the ileocecal valve is difficult because of its angled anatomy. In such situations, we passed the stricture with the ERCP catheter with a movable tip (Swing Tip Cannula, Olympus). Subsequently, the contrast medium was injec-
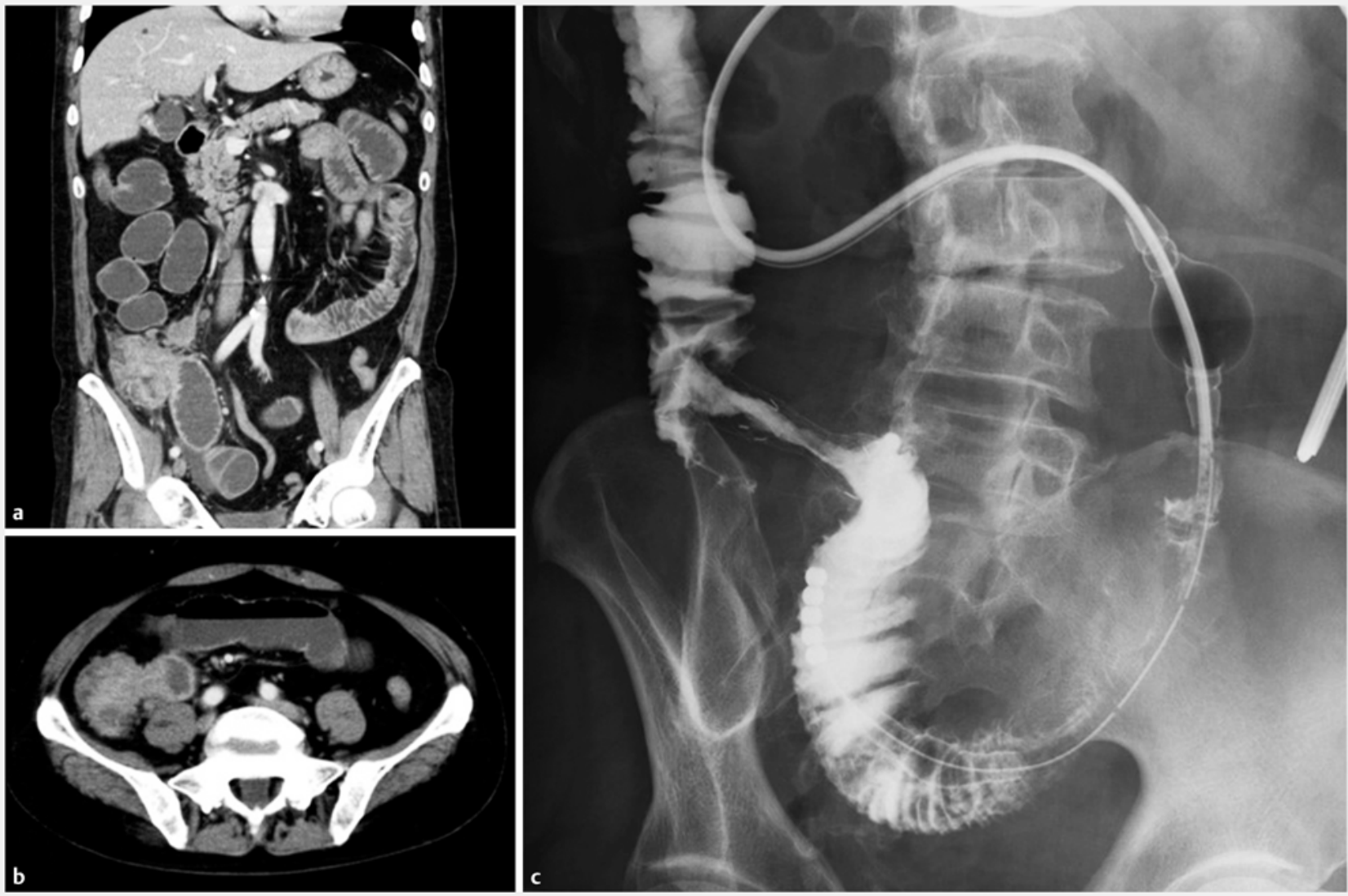

- Fig. 1 Images of Patient 1. a, b Contrast-enhanced computed tomography scan reveals thickened ileocecal stenosis with proximal dilation of the colon and distal small intestine. c Contrast medium was injected from the decompression tube, revealing the stenosis and terminal ileum clearly. 

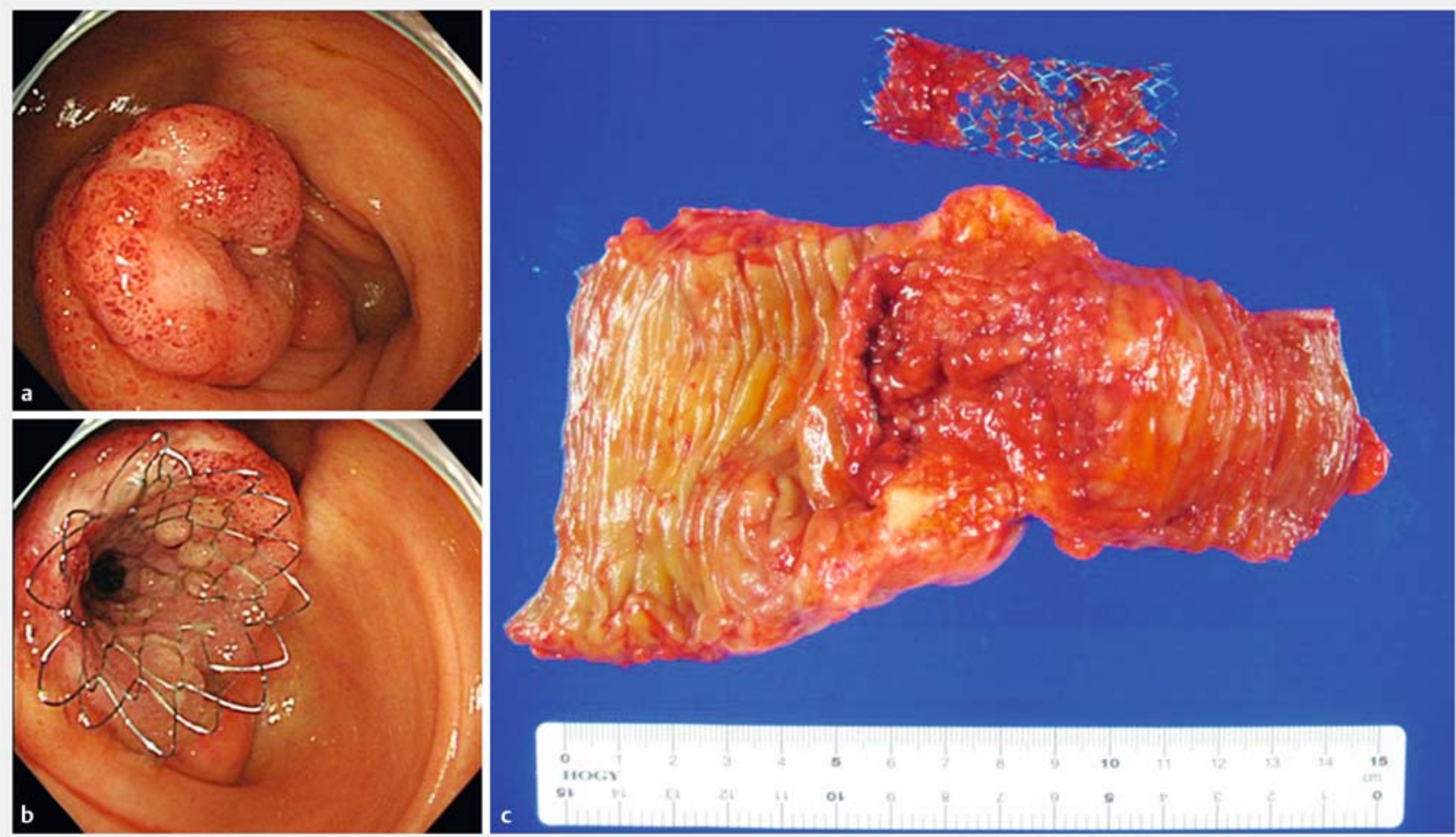

- Fig. 2 Images of Patient 3. a Neoplastic changes in the ileocecal valve. b Stenting for ileocecal valve. c Surgically resected specimen.

ted through the catheter to define the degree, length, and site of the stricture ( $\vee$ Fig. $3 a$ ). The SEMS was advanced over the guidewire and placed with a combination of endoscopic and fluoroscopic guidance ( $\triangleright$ Fig. $\mathbf{2 b}, \triangleright$ Fig. 3b). An uncovered Niti$S$ colonic stent (Taewoong Medical, Seoul, Korea), $18 \mathrm{~mm}$ in diameter, $6 \mathrm{~cm}$ in length, was used in all cases. SEMS placement was technically successful in all 4 cases.

The appropriate position of the SEMS was confirmed using abdominal radiographs a day after the procedure, all patients had a low-residue diet after SEMS placement and they were discharged about 1 week after stent placement. All 4 patients underwent laparoscopic ileocecal hemicolectomy without stoma creation within 3 weeks after the stent procedure and had no postsurgical complications ( $\triangleright$ Table $\mathbf{1}$ ).

Simultaneously we performed colonic stenting in 88 cases. The mean duration for the procedure was $27.2 \mathrm{~min}$ (range, 8 $105 \mathrm{~min}$ ) and the technical success rate was $97.7 \%(86 / 88)$. In ileocecal stenting, the mean duration for the procedure was $29.6 \mathrm{~min}$ (range, 20-47 min) and the technical success rate was $80 \%(4 / 5)$. No significant difference was found in the mean time for ileocecal stenting compared with other sites. In 1 case, selecting the oral side by the guidewire was difficult because the obstruction was complete and long.

\section{Discussion}

Ileocecal obstruction treated as malignant obstruction in rightsided colon (MORC) traditionally has been resected urgently with primary anastomosis without the need for formal bowel preparation or stoma formation [1]. This is mainly because postoperative outcomes of emergency surgery in MORC were comparable with elective surgery based on previous reports [2]. However, recent studies have noted that mortality rates and complications associated with emergency surgery for MORC were higher than those associated with elective surgery [3]. SEMS placement has been widely performed for malignant colorectal obstruction and can serve as a bridge to surgery (BTS) in patients with operable cancers. In the 2014 European Guideline on colonic stenting, SEMS placement as a BTS in curative setting was recommended for patients with increased risk of postoperative mortality, i.e., American Society of Anesthesiologists (ASA) Physical Status $\geq$ III and/or age $>70$ years. However, many studies reported that stenting as BTS for left-sided colonic obstruction has lower mortality and morbidity than emergency surgery [4]. Although reports on MORC are relatively few, reports showing efficacy and safety have been increasing in recent years $[5,6]$. Only a few studies have been reported for ileocecal obstruction [7, 8].

Placing SEMS for ileocecal obstruction is technically challenging for the following reasons. The long distance from the anus and tortuosity of the bowel make an ileocecal lesion difficult to reach endoscopically. Furthermore, passing through the stenosis is difficult because of the ileocecal valve's angled anatomy. 

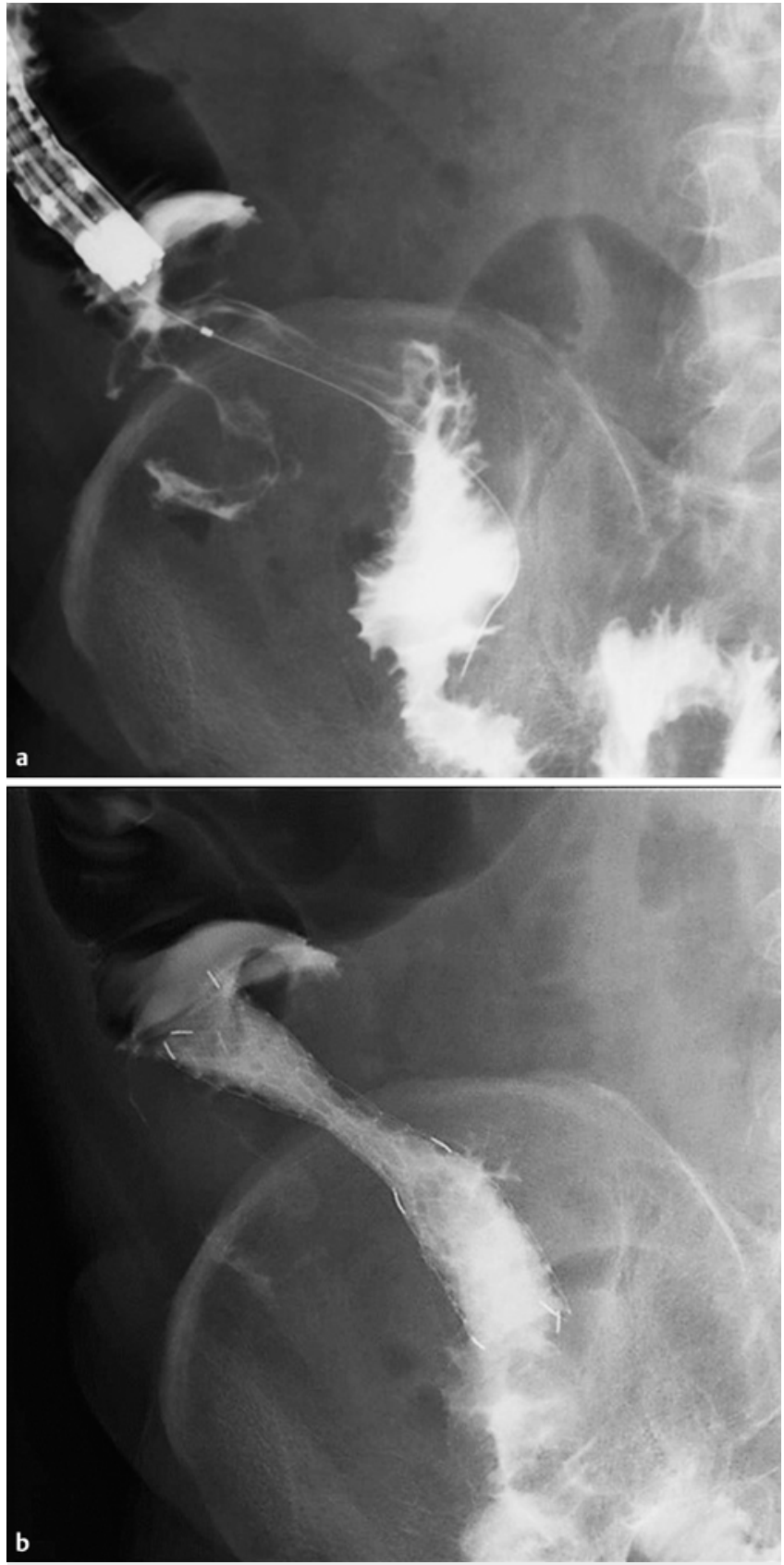

- Fig. 3 Images of Patient 4. a Under endoscopic and fluoroscopic guidance, the contrast medium is injected through the catheter to define the degree, length, and site of the stricture. $\mathbf{b}$ The self-expandable metallic stent is placed with fluoroscopic guidance.

We performed enema for preparation and washed away feces to maintain a clear endoscopic view during insertion (if possible, use of a water jet is desirable), and the scope was able to reach the ileocecal region. We successfully passed the ileocecal obstruction by using the ERCP catheter with a movable tip. When the decompression tube was deployed before stenting, contrast medium injection from the decompression tube was effective for assessing the oral side of the intestinal tract and useful for seeking the guidewire. In 1 case, selecting the oral side by the guidewire was difficult. Because the tumor was too large to be covered with SEMS and likely to be perforated, we abandoned stenting and elective surgery was performed after the decompression tube was placed.

Appropriate patient selection is believed to result in a high success rate and low complication rate for stent insertion. Stent insertion allows intestinal decompression and mechanical bowel preparation. It also enables preoperative evaluation for clinical staging of the patient's general condition and comorbidities and treatment of malnutrition, followed by appropriate management before radical surgery. A decompression tube can be placed for BTS, but SEMS insertion into colonic obstructions on not only the left side, but also on the right side, has several benefits compared with decompression tube placement, such as the clinical success rate and patient quality of life [9]. Elective surgery could avoid colostomy and allow laparoscopic surgery [10]. Laparoscopic surgery has been reported to have a lower risk of surgical site infection and better postoperative recovery because it is minimally invasive [11].

Although the effects of long-term placement are unknown, stent insertion itself can be palliative for inoperable cases or when clinical benefit is unlikely. Avoiding surgery and stenting for palliation would be effective treatment options. In ileocecal stenting, the stent port side is the ileum. Therefore, stents with lower axial force would be preferable. A Niti-S stent with an 18$\mathrm{mm}$ diameter, which has lower axial force, was used in all cases. No procedure-related complications and no ulcer formations were observed in the surgically resected specimen.

\section{Conclusion}

In conclusion, stenting for ileocecal obstruction is considered effective and safe, and may be an alternative treatment option in ileocecal obstruction. This procedure enables bowel decompression for subsequent elective surgery and allows further preoperative evaluation. Elective surgery could allow laparoscopic surgery. In addition, unnecessary surgery can be avoided by stenting when clinical benefit is unlikely.

\section{Competing interests}

None

\section{References}

[1] Phillips RKS, Hittinger R, Fry JS et al. Malignant large bowel obstruction. Br J Surg 1985; 72: 296-302

[2] Recipi A, Adler DG, Gibbs CM et al. Stenting of the proximal colon in patients with malignant large bowel obstruction: techniques and outcomes. Gastrointest Endosc 2007; 66: 940 - 944

[3] Hsu TC. Comparison of one-stage resection and anastomosis of acute complete obstruction of lest and right colon. Am J Surg 2005; 189: 384-387

[4] Van Hooft JE, van Halsema EE, Vanbiervleit G et al. Self-expandable metal stents for obstructing colonic and extracolonic cancer: European Society of Gastrointestinal Endoscopy (ESGE) Clinical Guideline. Gastrointestinal Endosc 2014; 80: 747 - 761 
[5] Amelung F], Consten EC], Siersema PD et al. A population-based analysis of three treatment modalities for malignant obstruction of the proximal colon: Acute resection versus stent or stoma as a bridge to surgery. Ann Surg Oncol 2016; 23: 3660-3668

[6] Ji WB, Kwak JM, Kang DW et al. Clinical benefits and oncologic equivalence of self-expandable metallic stent insertion for right-sided malignant colonic obstruction. Surg Endosc 2017; 31: 153-158

[7] Saida Y, Enomoto T, Takabayashi K et al. Outcome of 141 cases of selfexpandable metallic stent placements for malignant and benign colorectal stricture in a single center. Surg Endosc 2011; 25: 1748 1752

[8] Sasaki T, Yoshida S, Isayama $\mathrm{H}$ et al. Metallic stent placement for malignant enteral obstruction based on the type of enteral stent. Gastroenterol Endosc 2015; 57: 172 - 184
[9] Moroi R, Endo K, Ichikawa R et al. The effectiveness of self-expandable metallic stent insertion in treating right-sided colonic obstruction: A comparison between SEMS and decompression tube placement and an investigation of the safety and difficulties of SEMS insertion in right colons. Gastroenterol Res Pract Epub 2014; 2014: 372918 Epub 2014 Dec 16

[10] Zhang Y, Shi J, Shi B et al. Self-expanding metallic stent as a bridge to surgery versus emergency surgery for obstructive colorectal cancer: a meta-analysis. Surg Endosc 2012; 26: 110-119

[11] Neudecker J, Klein F, Bittner R et al. Short-term outcomes from a prospective randomized trial comparing laparoscopic and open surgery for colorectal cancer. Br J Surg 2009; 96: 1458-1467 